\title{
Estimating the population size of migrating Tibetan antelopes Pantholops hodgsonii with unmanned aerial vehicles
}

\author{
Jianbo Hu, Xia omin Wu and Mingxing Da
}

\begin{abstract}
Data on the distribution and population size of the Near Threatened Tibetan antelope Pantholops hodgsonii are necessary to protect this species. Ground-based count surveys are usually carried out from a long distance to avoid disturbing the sensitive animals, and on calving grounds or along migration routes where they are seasonally concentrated. This can result in underestimation of population sizes if terrain features obstruct the view and high concentrations of animals make estimating numbers difficult. Here we test the efficacy of unmanned aerial vehicles (UAVs) for gathering population data for the Tibetan antelope. We conducted the study south of a known calving ground, at the foot of Sewu Snow Mountain, in the Chang Tang National Nature Reserve, China. The UAV did not appear to disturb the animals and resulted in more accurate counts than ground-based observations. A total of 23,063 Tibetan antelopes were identified in twelve orthoimages derived from c. 4,000 aerial photographs. In the first flight area 7,671 females and 4,353 calves were identified (proportion of calves: $36.2 \%)$. In the second flight area 7,989 females and 3,050 calves were identified (proportion of calves: $27.6 \%$ ). Two flights over the same area revealed the direction and speed of moving Tibetan antelope groups. Image resolution, which can be controlled with flight planning, was an important factor in determining the animals' visibility in the photos. We found that UAV-based surveys outperformed ground-based surveys, and that larger UAVs are preferable for this application.
\end{abstract}

Keywords Aerial survey, Chang Tang National Nature Reserve, drone, Pantholops hodgsonii, population estimation, Tibetan antelope, UAV, unmanned aerial vehicle

\section{Introduction}

The Tibetan antelope or chiru Pantholops hodgsonii is 1 endemic to the Qinghai-Tibet Plateau in remote regions of western China. Females migrate between winter

JiAnbo Hu (Corresponding author) and MingXING DAI Tianjin Research Institute for Water Transport Engineering, Ministry of Transport, Tianjin 300456, China E-mail whogamble@hotmail.com

XIAOMIN WU Northwest Institute of Endangered Zoological Species, Shanxi Institute of Zoology, Xi'an, China

Received 17 September 2017. Revision requested 18 October 2017.

Accepted 3 November 2017. First published online 26 April 2018. rutting grounds and summer calving grounds (Leslie \& Schaller, 2008). Despite the remoteness and vastness of their habitat, the species was at risk of extinction during the $1980 \mathrm{os}$ and 1990s as a result of poaching for its fine wool, known as shahtoosh (Harris et al., 1999). Consequently, the Tibetan antelope is listed under first class protection in China (World Heritage Encyclopedia, 2016), included in Appendix I of CITES (CITES, 2017), and categorized as Near Threatened on the IUCN Red List (IUCN, 2016). Although populations have grown following anti-poaching efforts (Bleisch et al., 2009; Wu \& Zhang, 2011; Buzzard et al., 2012), development of animal husbandry, infrastructure development (railways and highways) and fencing of pastureland are putting increasing pressure on the species (Xia et al., 2007; Fox et al., 2009). Understanding the seasonal migration and habitat of the Tibetan antelope is crucial for developing policies to ensure its protection, and accurate survey data are needed to provide information on the species' distribution and population size.

Ground-based survey methods include block counts, vehicle or walking transects, and radial point sampling (Schaller et al., 2007). Tibetan antelopes, especially females with calves, are sensitive to the appearance of humans and vehicles. Surveys are therefore usually carried out from afar (c. $1 \mathrm{~km}$ ). This is appropriate during the non-migratory season, when groups are small and evenly distributed across the plateau, but can result in underestimates where terrain features obstruct the view or when animals occur in large groups. During migration, female Tibetan antelopes move to the calving grounds, calve during late June or early July, and then start their return migration (Schaller et al., 2006). Because of this seasonal concentration, calving grounds are suitable locations to survey females (Buzzard et al., 2012). However, determining population size using ground-based survey methods is difficult because movement of animals can cause large fluctuations in density estimates, inclement weather often limits visibility, many areas are hard to access (Schaller et al., 2006), and calves are difficult to detect from afar. Tracking individuals using collars equipped with a Global Positioning System (GPS) unit is useful for identifying calving grounds, migration corridors and suitable habitats (Buho et al., 2011; Manayeva et al., 2017; Zhang et al., 2016), but new aerial survey methods are required for accurate population size estimates.

Unmanned aerial vehicles (UAVs, or drones) equipped with sensors (e.g. digital cameras) are a new platform for 
remote sensing (Hodgson et al., 2016; Hodgson \& Koh, 2016b). Aerial counts using aeroplanes and helicopters agitate animals on the ground when flown at altitudes at which animals can be counted effectively, but drones can fly at lower altitudes and lower speeds, allowing them to take high resolution images at the desired frequency. Because of these advantages, drones are being used increasingly in conservation biology (Koh \& Wich, 2012; Anderson \& Gaston, 2013). Recent reviews of UAV use (Chabot \& Bird, 2016; Christie et al., 2016) concluded they are particularly useful for monitoring wildlife and habitats in places that are difficult to access, e.g. at distant locations, in marine environments (whales; Koski et al., 2009) or in tree canopies (orang-utans; Koh \& Wich, 2012). UAVs can also be used to observe sensitive species such as birds (Rodríguez et al., 2012; Liu et al., 2015), or aggressive species such as elephants (Vermeulen et al., 2013) and alligators (Watts et al., 2010). Here we examined the efficacy of UAVs for estimating the population size and movement of Tibetan antelopes.

\section{Study area}

The study area is south of a known calving ground at the foot of Sewu Snow Mountain, in the 334,000 $\mathrm{km}^{2}$ Chang Tang National Nature Reserve in the Tibetan Autonomous Region of China (Fig. 1). The average altitude of the Reserve is $>4,800 \mathrm{~m}$, and the climate is continental, dry and cold. Precipitation is rare and sparse, and frequently falls as snow, sleet or hail, even in the summer. There is permanent snow above $5,500 \mathrm{~m}$.

The calving ground was identified during a population survey in 2013 by tracking 15 females with Beidou (the Chinese satellite navigation system) collars before the calving season (Lei, 2013). Over 100,000 females were observed at the site. Data from the collars showed that the migration routes were south of the calving ground (Fig. 1b).

Two UAV flight areas, FA1 (Fig. 1C) and FA2 (Fig. 1d), were established on the edge of two return migration routes, c. $45 \mathrm{~km}$ and c. $75 \mathrm{~km}$ from the calving ground, respectively. FA1 is characterized by flat alluvial meadows, and FA2 is dominated by mountains. A third flight area, $\mathrm{FA}_{3}$ (Fig. 1e), was set up by a pond at the foot of a mountain, c. $75 \mathrm{~km}$ from the calving ground, where a group of male Tibetan antelopes had been found. All flight areas were above 5,000 $\mathrm{m}$.

\section{Methods}

\section{UAV operation}

The electric fixed-wing UAV Trimble $\mathrm{UX}_{5}$ (Trimble, Sunnyvale, USA; wingspan $1 \mathrm{~m}$, weight $2.5 \mathrm{~kg}$, standard cruise speed $80 \mathrm{~km} \mathrm{~h}^{-1}$, flight height $75-750 \mathrm{~m}$, standard maximum flight duration 50 minutes, image resolution
$2.4-24 \mathrm{~cm}$, wind resistance $<65 \mathrm{~km} \mathrm{~h}^{-1}$, maximum distance of remote control $5 \mathrm{~km}$ ) was chosen for its ease of use. The $\mathrm{UX}_{5}$ is equipped with a GPS and an inertial measurement unit. These two sensors determine position and altitude in flight, and record the position and orientation at the moment an image is captured. A Sony a5100 APS-C digital camera was located in the head of the $\mathrm{UX}_{5}$ (photo size 24 megapixels, focal length $15 \mathrm{~mm}$ ). The image resolution or ground sample distance of an image is defined as the side length of the square of ground area covered by one pixel in the image, and is determined by camera parameters, flight height and terrain characteristics.

The ground control station is used to set flight characteristics (i.e. working area size and location, image overlap, height, take-off and landing positions, wind and landing directions). After uploading the flight plan to the $\mathrm{UX}_{5}$, the ground control station is required only for launching the UAV with the aid of a catapult, monitoring, and landing. Accurate and predictable landing requires a flat strip, $150 \times 30 \mathrm{~m}$, clear of wood, mounds or rocks. A single trained person can operate the $\mathrm{UX}_{5}$, but two trained operators are recommended to minimize any risk that may be caused by handling errors. In this study one operator held the ground control station to operate the software during the flight (flight plan, launching, monitoring, and landing), and the other handled the UAV before launching (preparation) and after landing (preparation for the next flight or packing).

\section{Flight characteristics}

The three flight areas and the individual flights were not fully planned ahead of time. Rather, decisions on where and when to use the UAV were made when herds of females and calves were located. All flights took place during 14-25 July 2016, after the calving period had ended. Flight characteristics for the 12 flights were nearly identical except for time and location (Fig. 1). The UAV took off and landed in the same ground position for each flight, and several flights shared the same take-off and landing position. Positions for take-off and landing were in locations where we found large groups of Tibetan antelopes and where it was difficult for them to detect us. Flight height was $150-200 \mathrm{~m}$ above the ground, so that adults and calves were discernible in photos (image resolution: $4-5 \mathrm{~cm}$ ). The image overlap rate was $50 \%$, and the flight duration was limited to c. $30 \mathrm{~min}$ because of the large amount of battery power needed to keep the UAV airborne in the low air pressure environment associated with high altitudes. The area covered by a single flight was therefore limited to $\mathrm{c} .3 \mathrm{~km}^{2}$. To acquire sharp images, the shutter speed was set at $<1 / 3,000 \mathrm{~s}$, and the ISO (camera sensor sensitivity) was set at $100-400$, depending on the ambient light conditions. In total, the flights generated c. 4,000 images. 

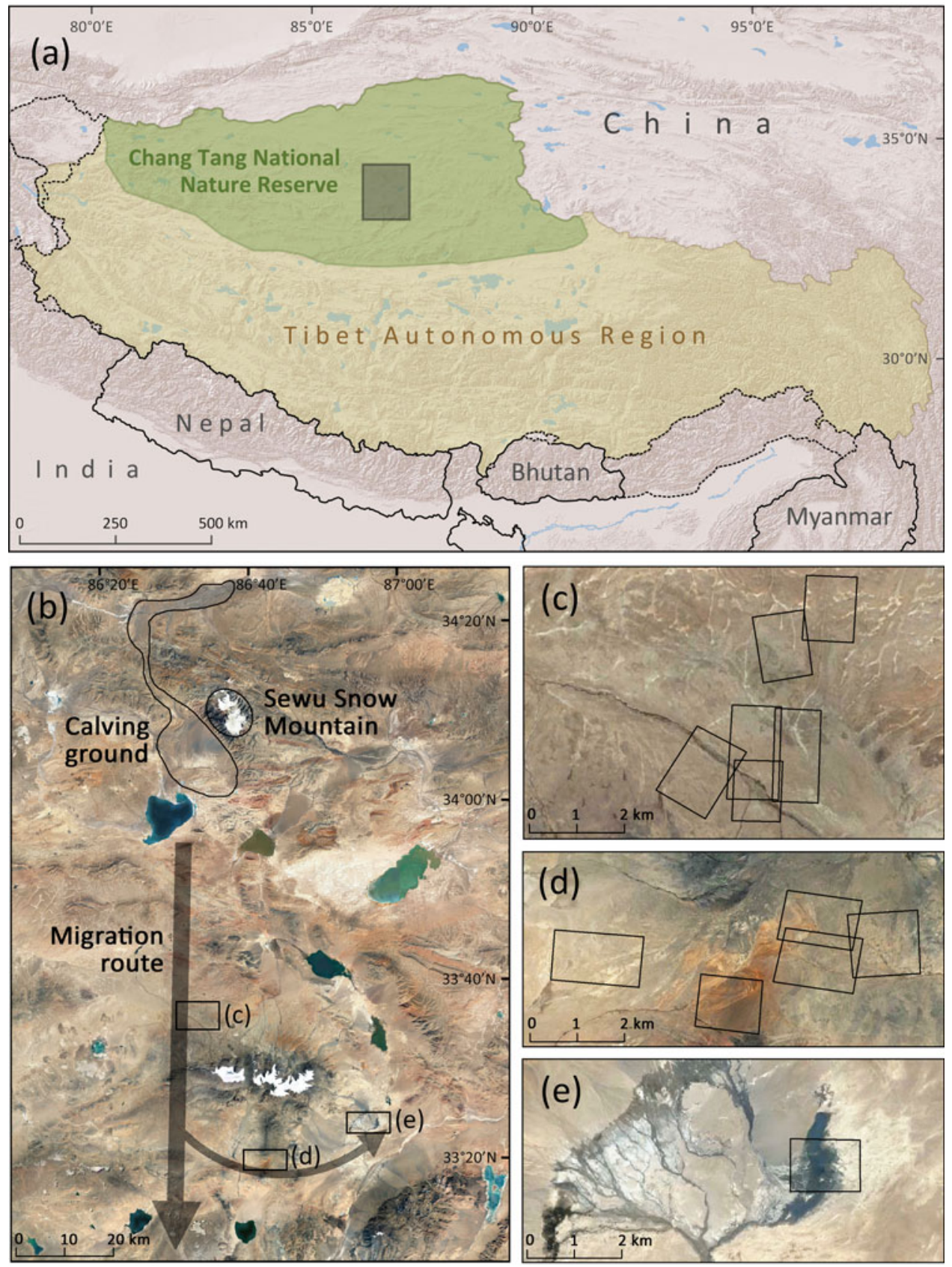

FIG. 1 Location of twelve UAV flights undertaken in July 2016 in three flight areas. (a) Location of the study area (grey rectangle) in the Chang Tang National Nature Reserve in China. (b) Location of the three flight areas to the south of a known calving ground at the foot of Sewu Snow

Mountain. (c) Coverage of six flights (14-15 July) in FA1. (d) Coverage of five flights ( 25 July) in FA2. (e) Coverage of one flight (24 July) in FA3. Flight areas FA1 (c) and FA2 (d) were on the edge of two return migration routes, flight area $\mathrm{FA}_{3}(\mathrm{e})$ is in a habitat where a group of male Tibetan antelopes had been found.
Ground observation for flight preparation, UAV disturbance assessment, and traditional counting

Ground observation, using a powerful telescope with a magnification value of $\times 10-22$, was used for UAV flight preparation, to observe the antelopes' reactions during UAV flights and to count the population in the traditional way. During the UAV flight preparation, ground observation was used to find a suitable position for launching and landing, ensuring a sufficient distance between our vehicles and the antelopes to avoid disturbing the animals. The optimal position is close enough to the antelopes to facilitate the required flight duration, and far enough to remain undetected by them.
Suitable positions were determined by observing whether the groups changed direction (away from us) or moved faster when our vehicles appeared.

During each flight the UAV passed 8-12 times above the group along parallel lines 125-150 m apart. We assessed any disturbance to the animals caused by the UAV's presence through ground observation, the criterion used being whether the groups changed direction (moved away from us) or moved faster when the UAV approached.

During the flight in $\mathrm{FA}_{3}$, ground observation was also used to count the population (all individuals were standing relatively still in a pond or on a shoal). The ground-based count was compared to the UAV-based count. 


\section{Animal visibility analysis}

The visibility of animals in an aerial photograph is defined as the ease with which individuals can be identified with the naked eye. It is not possible to quantify animal visibility because there is no absolute reference point. We therefore subjectively judged animal visibility by the time taken to identify individuals in the images, with higher visibility requiring less time per individual identified. The relationship between image resolution and animal visibility was then analysed. Animal visibility is positively correlated with resolution, which is determined by the flight height of the UAV above the ground. Although the UAV flew at a constant height above the launching and landing position in each flight, the terrain was not always flat. Ground resolution in the aerial photos changed with the terrain and could be calculated if the terrain was known:

$$
r=(a-t) \times p \div f
$$

where $r$ denotes the resolution of an aerial photo, $a$ is the altitude recorded by the GPS unit in the UAV when the photo was taken, $t$ is the altitude of the terrain based on the longitude and latitude information of the photo location (van Zyl, 2001), and $p$ and $f$ are the pixel size of the camera and focal length of the lens, respectively.

\section{Orthoimages for UAV counting and estimation of speed of movement}

All photos were acquired in an aerial photogrammetric way, characterized by shooting positions arranged like the nodes of a large grid. The field of view of every image has at least four partially overlapping neighbours, which is a requirement of aerial photogrammetry. The images were packed and processed using Pix 4 Dmapper (Pix4D, Lausanne, Switzerland). One of the outputs is a geometrically corrected and mosaicked orthoimage for each flight (Fig. 2). All 12 orthoimages were then added as background images for counting using $\operatorname{ArcGIS} 10.3$ (Esri, Redlands, USA). The orthoimage in $\mathrm{FA}_{3}$ was also used to show the difference between the UAV-based population estimate and the ground-based survey method. Using this approach, every individual Tibetan antelope was identified, positioned and labelled. If an individual moved quickly during the UAV flight, it had several virtual clones in the orthoimage. If it moved slowly, it looked much longer in the orthoimage. If it did not move, it looked the same as in the original photos.

Two flights in FA2 covered an overlapping area, with a 30 min interval ( $25 \mathrm{~min}$ flight time and $5 \mathrm{~min}$ preparation) between them. During the interval, the groups of antelopes were moving slowly, and hundreds of individuals were identified in the images from both flights. This presented a doublecounting issue requiring a significant amount of cross- checking. However, the mapping of individuals between those flights allowed us to determine the direction and speed of movement for different groups, based on the fact that the groups kept to a recognizable formation during migration.

\section{Results}

\section{UAV disturbance assessment}

We found that the migrating animals (females and calves) in $\mathrm{FA} 1$ and $\mathrm{FA}_{2}$ were more sensitive to approaching vehicles (safe distance $1.5-2 \mathrm{~km}$ ) than the males in $\mathrm{FA}_{3}$ (safe distance $0.6-1 \mathrm{~km})$. Our ground observations indicated that neither females nor males reacted to the UAV flights. No blurred individuals were found in the aerial photos, demonstrating that they were not running when the UAV flew over.

\section{Animal visibility}

Different levels of image resolution were not planned ahead of the flights, but did occur during the survey. Three typical photos are presented in Fig. 3. The highest resolution $(1 \mathrm{~cm})$ image was taken at a height of $32 \mathrm{~m}$ above the ground, caused by an unexpectedly high mound in the area covered by one of the flights. In this photo, the ears, tail, and dark brown back of each individual can be identified. The medium resolution $(4 \mathrm{~cm})$ photo was taken at a height of $125 \mathrm{~m}$, which is representative of most of the aerial photos taken in FA1 (flat), and in some parts of FA2 (mountainous). This resolution was sufficient to identify individual calves. The pairs of females and their calves were all moving in the same direction, showing that they were a group on migration. In addition, habitat differences can be observed in the medium resolution images (i.e. distinct colouring between white and green alluvial meadows). The lowest resolution $(8 \mathrm{~cm})$ photo was taken at a height of $250 \mathrm{~m}$ because the launch and landing position was hidden behind a peak that is higher than the area covered by that flight. Such photographs were only taken in FA2. This resolution is just fine enough for identifying adults. Although a calf is not discernible on its own in these images, it could with careful analysis be identified near its mother. Shadows played an important role in the identification of individual animals in these low-resolution images, because they provide a strong contrast to the sandy background. Had these photos been taken on a cloudy day, antelope identification may have been impossible.

\section{Animal counts}

Of the 12 UAV flights, one took place in a habitat where a group of male Tibetan antelopes had been found; the other eleven flights were conducted on the edge of two 

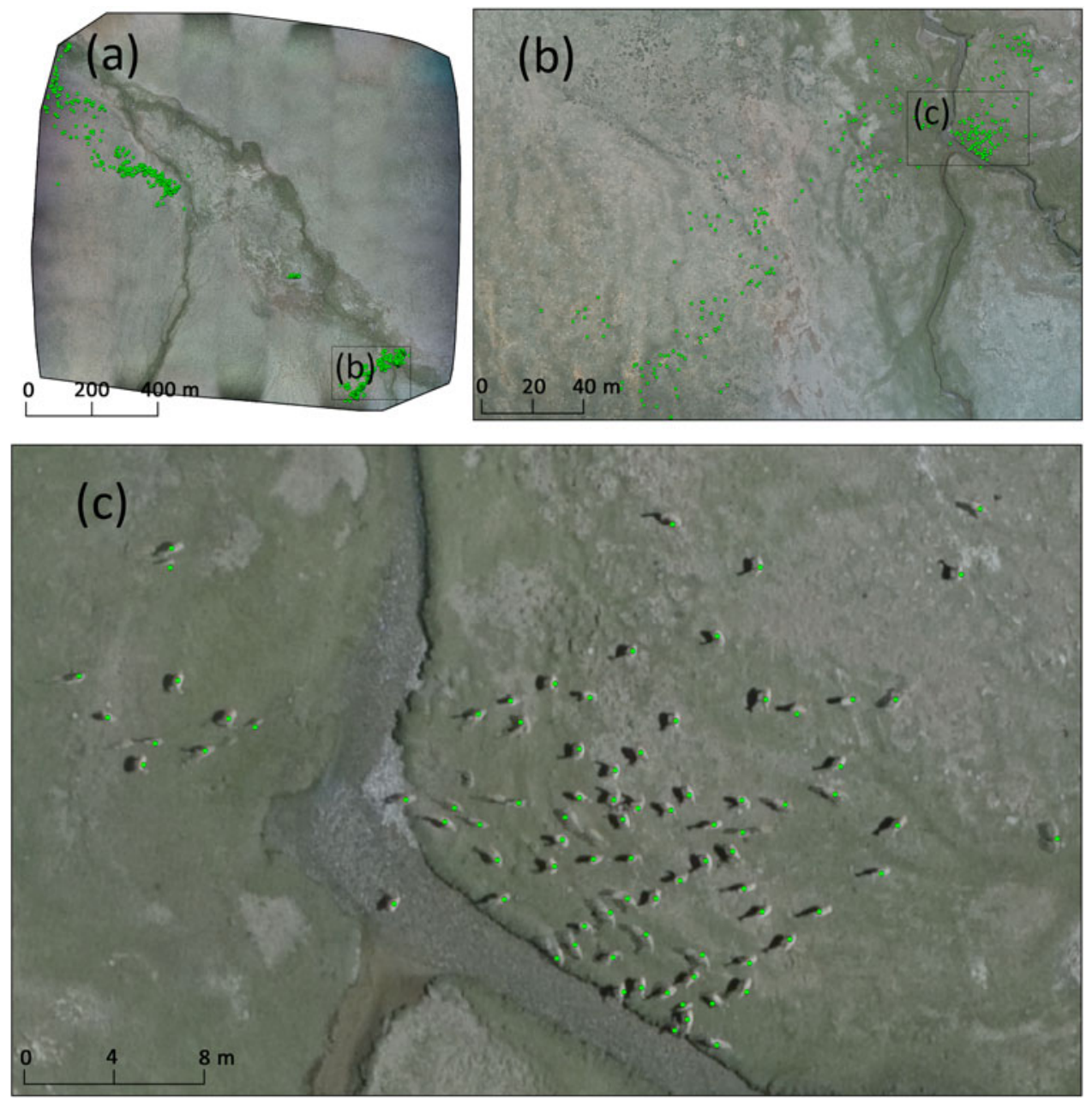

FIG. 2 Tibetan antelope identification based on the orthoimage (mosaicked image obtained from hundreds of aerial photos) from one flight in FA1. Each green point represents one individual antelope; together they provide information on the size of the population and its distribution. (a) The entire orthoimage. (b) Enlarged view of the subset in (a). (c) Enlarged view of the subset in (b).
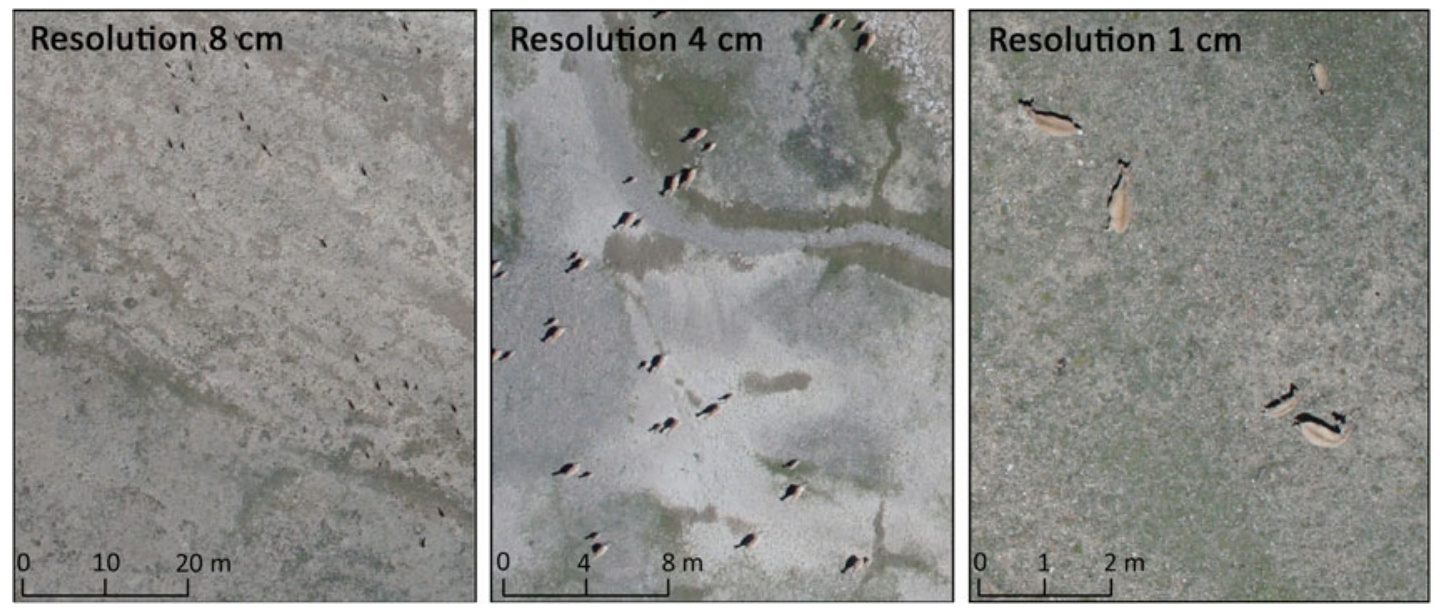

FIG. 3 Aerial photographs of Tibetan antelopes taken at flight heights of c. 250, 125, and $32 \mathrm{~m}$ above the ground, respectively, with a corresponding image resolution of c. 8,4 , and $1 \mathrm{~cm}$.

return migration routes. We first counted the group of males in FA3 (Fig. 4). The group was small and all individuals were standing still in a pond or on a shoal. Before the flight, we estimated the number of individuals at $20-$ 40, although we knew that some animals may not be visible from our vantage point because they were hidden behind others. The aerial photo revealed that there were 85 individuals in the pond and six on the shoal.

The difficulty of counting animals in the images from the remaining eleven flights varied, depending on their visibility 

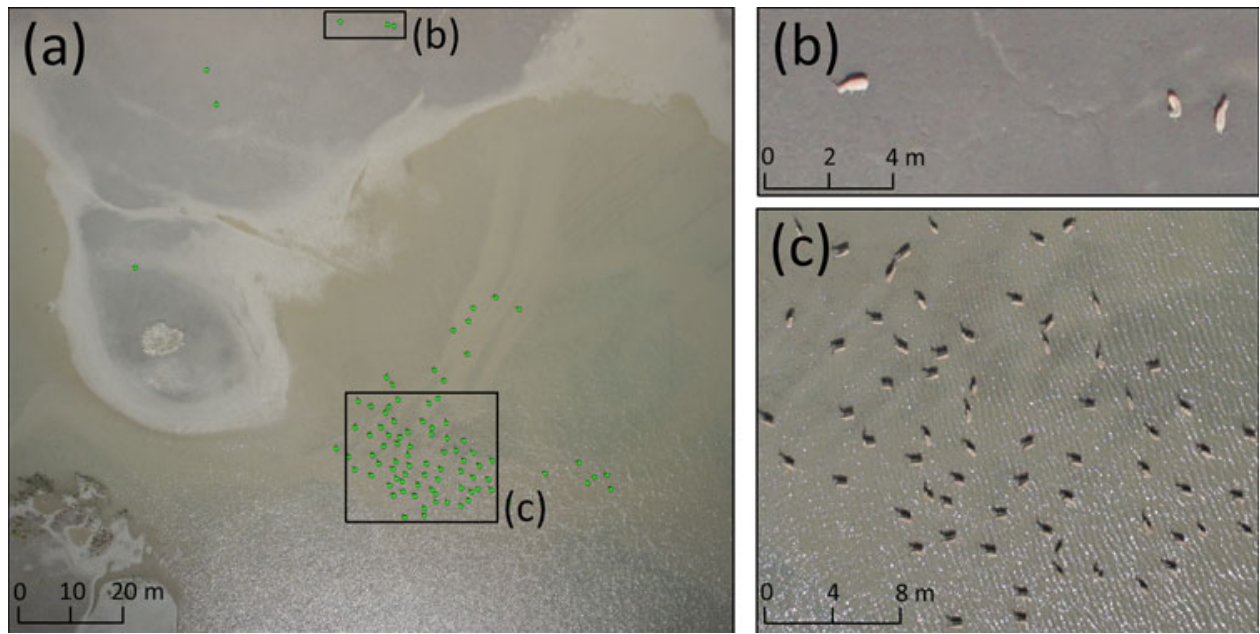

Fig. 4 A group of male Tibetan antelopes in flight area FA3. (a) 85 antelopes in the pond and six on the shoal, marked with dots. (b) Enlarged view of the shoal subset in (a). (c) Enlarged view of the pond subset in (a). in the photos. It took $>100 \mathrm{~h}$ to count individual animals in the orthoimages. Cross-checking the images to avoid double-counting virtual clones of individuals was particularly time-consuming. The low resolution $(8 \mathrm{~cm})$ orthoimages took at least twice as long to assess compared with the medium resolution $(4 \mathrm{~cm})$ orthoimages, because low animal visibility requires careful analysis. In the eleven flights over FA1 and FA2, the total number of individuals counted was 23,063 . The error in animal counts could not be estimated, although some degree of error is likely because calves were hard to identify in the low resolution $(8 \mathrm{~cm})$ orthoimages. In FA1, 7,671 females and 4,353 calves were identified (proportion of calves $36.2 \%$ ). In FA2, we counted 7,989 females and 3,050 calves (proportion of calves 27.6\%).

\section{Animal movements}

Based on similarities in the point distribution patterns between the two orthoimages of the overlapping flights in FA2 that occurred within 30 min of each other, we concluded that there were at least three groups of antelopes moving in different directions (Fig. 5). The group on the left hand side of the images was moving northwards down the hill, the group in the centre was moving eastwards across the valley, and the group on the right hand side was moving northwest up the hill. The speed of movement was calculated as 160,320 , and $50 \mathrm{~m} \mathrm{~h}^{-1}$ for the left, centre, and right groups, respectively.

\section{Discussion}

\section{Effectiveness of using UAVs for antelope surveys}

We found that the UAV did not disturb the Tibetan antelopes surveyed. They also showed no reaction to several eagles that were hovering in the air at an altitude of c. $100 \mathrm{~m}$ during our flights in FA2. The antelopes apparently do not feel threatened by anything hovering in the sky, even though eagles are potential calf predators and the UAV has a bird-like silhouette and emits some noise during flight. Animal disturbance by UAVs has been observed in birds, zebras, wildebeest, elephants, giraffes and various antelope species (Drever et al., 2015; Mcevoy et al., 2016; Borrelle \& Fletcher, 2017), but the response to the presence of a UAV varies between different species and environments (Hodgson \& Koh, 2016a). For the observation of Tibetan antelopes a fixed wing UAV is the best choice, because rotor wing UAVs are noisier and their batteries do not support flights of several $\mathrm{km}$ at an altitude of $5,000 \mathrm{~m}$. The flight height of 150-200 $\mathrm{m}$ used in this study is close to the minimum that ensures UAV safety in this mountainous area; a greater flight height would have made the acquisition of clear images difficult with the UAV's camera. Although animals do not appear visually disturbed by the UAV's presence, they could still be stressed by it. For these reasons we recommend a camera lens with a longer focal length, and a higher flight altitude, for future studies of this kind.

In summary, UAVs are suitable for estimating numbers of Tibetan antelopes. Ground observation significantly underestimated numbers because some animals were hidden behind others, which demonstrates the limitations of ground observation and the strength of aerial imaging. We counted a total of 23,063 individuals in the aerial photos, but considering that several thousands of individuals were probably double-counted (Fig. 5), the actual number of animals present in the flight areas was probably c. 20,000. This number does not take into account other groups migrating in different directions, and the individuals that we observed outside the flight areas, so it can be expected that the actual population size is much larger. For this pilot study, the fact that we successfully used a UAV to survey populations of Tibetan antelopes was more important than the absolute number of animals counted.

The proportion of calves was $36.2 \%$ in FA1 and $27.6 \%$ in $\mathrm{FA} 2$, similar to the results of previous surveys in other 


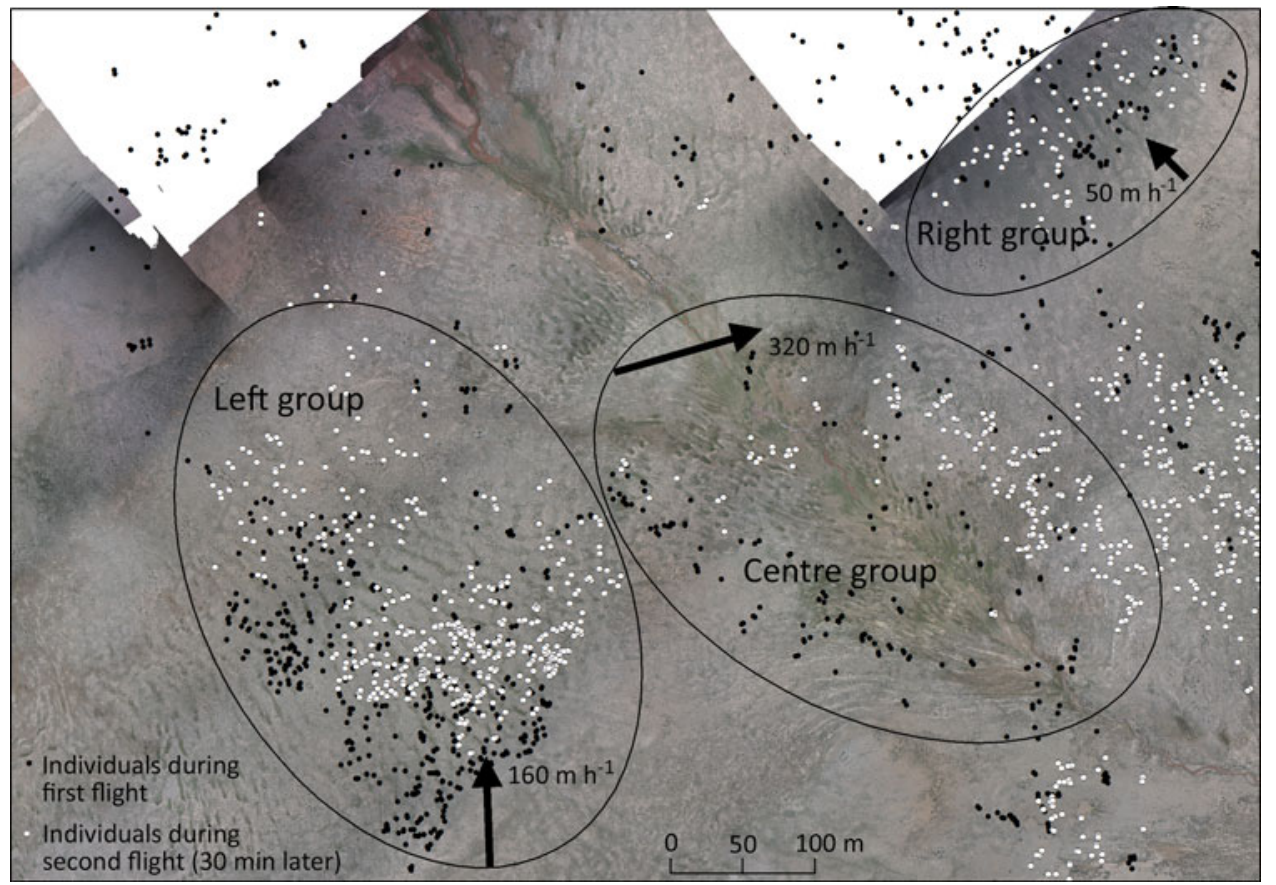

FIG. 5 Individuals identified in the overlapping area of two flights in flight area FA2 with a 30 min interval. Mapping the individuals identified in the two orthoimages reveals the direction and speed of movement (indicated by the direction and lengths of the arrows) of at least three groups of antelopes (indicated by the ovals). nature reserves. A survey on the migration routes in the Aru Basin in 1992 found a proportion of calves of c. $40 \%$ (Schaller, 2000). A calving ground survey in 2005 in the western Kunlun Mountains, Xinjiang, found that $16 \%$ of all females observed had not yet reached sexual maturity and $40 \%$ of the rest had young (proportion of calves 24.8\%) (Schaller et al., 2006). This low fecundity was attributed to heavy snowfall during the winter period, leading to poor physical condition of many animals. The lower proportion of calves seen in FA2 compared with FA1 could be an artefact of the lower resolution $(8 \mathrm{~cm})$ orthoimages and resulting low animal visibility in FA2.

UAV-based imagery also facilitates the measurement of movement. We identified three groups in FA2 moving in different directions and at different speeds. GPS tracking data has shown that return migration, at c. $300 \mathrm{~m} \mathrm{~h}^{-1}$, takes twice as long as calving migration (Buho et al., 2011), probably because calves on the return migration cannot move as quickly as the adults on their own during the calving migration. Our study revealed the slower movement of groups consistent with the presence of young calves. Although our findings are not robust, based on only three groups observed over half an hour, the use of UAVs for studying the movement of animal groups merits further examination.

\section{Lessons learned and outlook for future use}

One of our key findings from the application of a UAV for assessing Tibetan antelope populations is that image resolution determines count accuracy. The appropriate resolution of aerial photos was $4-5 \mathrm{~cm}$ for surveys along return migration routes, which enables the detection of newly born calves. The resolution required for effective counts could be lower at other times of the year, e.g. for surveys conducted during the winter rutting season. Resolution will vary with changes in the distance between the UAV and the ground. Therefore, in mountainous terrain flights should be carefully planned to ensure the required resolution. Animal visibility in aerial photographs is also a function of the contrast between the animals and the background, and ambient light conditions, and therefore flights should be planned to ensure sufficient resolution in situations where these factors make the detection of animals difficult. If image resolution and animal visibility are sufficiently high, it could also be possible to determine the age of an individual by measuring its back length (Vermeulen et al., 2013). The UX5 UAV used did not have sufficient flight time to conduct the multiple flights necessary to cover a large calving ground of hundreds of square kilometres (Schaller et al., 2006). Analysing the results of a single flight is easier than combining the results of multiple flights, because double-counting becomes increasingly problematic with the number of overlapping surveys. In the future, therefore, we intend to investigate the use of a larger, gas-powered fixed-wing UAV, with a flight duration of $>10 \mathrm{~h}$ at an altitude of $6,000 \mathrm{~m}$, which would allow us to survey a much larger area around the calving ground. To cover the entire calving ground area in one flight and acquire aerial photos with appropriate resolution, flight height needs to be higher and a camera lens with a longer focal length is required. We flew the UAV in an aerial photogrammetric way, with an overlap rate of $50 \%$ between images, to use orthoimages. If a population is large and individuals are scattered over an 
expansive area, surveys using non-overlapping aerial photos are both effective and more efficient.

In general, UAV-based surveys outperform groundbased surveys. The landscape around the calving ground includes muddy terrain that is difficult to access. Problems encountered regularly in ground-based surveys, such as obstructing terrain or poor visibility of individuals in dense groups can be eliminated by using UAVs, which offer a better viewing position. Ground vehicles also disturb the animals, making a pre-dug bunker necessary for close observation, an effort that is unnecessary for a UAV-based survey. A disadvantage of UAVs is that current models are costly and require skilled operators, but cheaper and simpler UAVs can be expected in the future. Ultimately, UAVs have the potential to greatly expand the range and efficiency of researchers conducting field surveys.

\section{Acknowledgements}

This work was funded by the Fundamental Research Funds for the Central Public Welfare Research Institutes (TKS160112), and the National Natural Science Foundation of China (General Program 31670439 and 31270437). We thank the organizers of the '2016 We and Tibetan Antelope' expedition, which allowed $>10$ staff to visit the study area. Our work was conducted under agreements with the Tibet Autonomous Region Forestry Bureau, which provided food, accommodation, guidance, and logistical support. We thank the photographers of China Central Television for their ground observations and Dr. Joanne Maio for her assistance with language editing.

\section{Author contributions}

$\mathrm{JH}$ and MD conceptualized the study and MD provided organizational support for the fieldwork. JH was responsible for the operation of the UAV, processed the aerial photos and identified the individuals in the orthoimages. XW identified a suitable study area and sampling time period and undertook the ground observations.

\section{References}

Anderson, K. \& Gaston, K.J. (2013) Lightweight unmanned aerial vehicles will revolutionize spatial ecology. Frontiers in Ecology and the Environment, 11, 138-146.

Bleisch, W.V., Buzzard, P.J., Zhang, H., Xü, D., Liu, Z., Li, W. \& Wong, H. (2009) Surveys at a Tibetan antelope Pantholops hodgsonii calving ground adjacent to the Arjinshan Nature Reserve, Xinjiang, China: decline and recovery of a population. Oryx, 43, 191-196.

Borrelle, S.B. \& Fletcher, A.T. (2017) Will drones reduce investigator disturbance to surface-nesting birds? Marine Ornithology, 45, 89-94.
Buho, H., Jiang, Z., Liu, C., Yoshida, T., Mahamut, H., Kaneko, M. et al. (2011) Preliminary study on migration pattern of the Tibetan antelope (Pantholops hodgsonii) based on satellite tracking. Advances in Space Research, 48, 43-48.

Buzzard, P.J., Wong, H.M. \& Zhang, H. (2012) Population increase at a calving ground of the Endangered Tibetan antelope Pantholops hodgsonii in Xinjiang, China. Oryx, 46, 266-268.

Снавот, D. \& BirD, D.M. (2016) Wildlife research and management methods in the 21st century: Where do unmanned aircraft fit in? Journal of Unmanned Vehicle Systems, 3, 137-155.

Christie, K.S., Gilbert, S.L., Brown, C.L., Hatfield, M. \& HANSON, L. (2016) Unmanned aircraft systems in wildlife research: current and future applications of a transformative technology. Frontiers in Ecology and the Environment, 14, 241-251.

CITES (2017) Convention on International Trade in Endangered Species of Wild Fauna and Flora. Appendices I, II and III. Https:// cites.org/sites/default/files/eng/app/2017/E-Appendices-2017-10-04. pdf [accessed o2 February 2018].

Drever, M.C., Сhabot, D., O'Hara, P.D., Thomas, J.D., Breault, A. \& Millikin, R.L. (2015) Evaluation of an unmanned rotorcraft to monitor wintering waterbirds and coastal habitats in British Columbia, Canada. Journal of Unmanned Vehicle Systems, 3, 256-267.

Fox, J.L., Dhondup, K. \& DorJi, T. (2009) Tibetan antelope Pantholops hodgsonii conservation and new rangeland management policies in the western Chang Tang Nature Reserve, Tibet: is fencing creating an impasse? Oryx, 43, 183-190.

Harris, R.B., Pletscher, D.H., Loggers, C.O. \& Miller, D.J. (1999) Status and trends of Tibetan plateau mammalian fauna, Yeniugou, China. Biological Conservation, 87, 13-19.

Hodgson, J. \& KoH, L.P. (2016a) A guide to using drones to study wildlife: first, do no harm. The Conversation. Https:// theconversation.com/a-guide-to-using-drones-to-study-wildlifefirst-do-no-harm-57069 [accessed o2 February 2018].

Hodgson, J.C. \& КоH, L.P. (2016b) Best practice for minimising unmanned aerial vehicle disturbance to wildlife in biological field research. Current Biology, 26, R404-R405.

Hodgson, J.C., Baylis, S.M., Mott, R., Herrod, A. \& Clarke, R.H. (2016) Precision wildlife monitoring using unmanned aerial vehicles. Scientific Reports, 6, 22574.

IUCN SSC Antelope Specialist Group (2016) Pantholops hodgsonii. In The IUCN Red List of Threatened Species 2016: e.T15967A50192544. Http://dx.doi.org/10.2305/IUCN.UK.2016-2. RLTS.T15967A50192544.en [accessed 6 February 2018].

KoH, L.P. \& W ICH, S.A. (2012) Dawn of drone ecology: low-cost autonomous aerial vehicles for conservation. Tropical Conservation Science, 5, 121-132.

Koski, W.R., Allen, T., Ireland, D., Buck, G. \& Smith, P.R. (2009) Evaluation of an unmanned airborne system for monitoring marine mammals. Aquatic Mammals, 35, 347-357.

LeI, W. (2013) Live cross: Antelopes on Sewu Snow Mountain. (ed. James), China Central Television. Http://english.cntv.cn/ program/newsupdate/20130702/104667.shtml [accessed o2 February 2018].

Leslie, JR, D.M. \& Schaller, G.B. (2008) Pantholops hodgsonii (Artiodactyla: Bovidae). Mammalian Species, 817, 1-13.

Liu, C.-C., Chen, Y.-H. \& Wen, H.-L. (2015) Supporting the annual international black-faced spoonbill census with a low-cost unmanned aerial vehicle. Ecological Informatics, 30, 170-178.

Manayeva, K., Hoshino, B., Igota, H., Nakazawa, T. \& Sumiya, G. (2017) Seasonal migration and home ranges of Tibetan antelopes (Pantholops hodgsonii) based on satellite tracking. International Journal of Zoological Research, 13, 26-37.

Mcevoy, J.F., Hall, G.P. \& Mcdonald, P.G. (2016) Evaluation of unmanned aerial vehicle shape, flight path and camera type for 
waterfowl surveys: disturbance effects and species recognition. PeerJ, 4, e1831.

Rodríguez, A., Negro, J.J., Mulero, M., Rodríguez, C., Hernandez-Pliego, J. \& Bustamante, J. (2012) The eye in the sky: combined use of Unmanned Aerial Systems and GPS data loggers for ecological research and conservation of small birds. PLoS ONE, 7, e50336.

Schaller, G.B. (200o) Wildlife of the Tibetan Steppe. University of Chicago Press, Chicago, USA.

Schaller, G.B., KanG, A., Cai, X. \& Liu, Y. (2006) Migratory and calving behavior of Tibetan antelope population. Acta Theriologica Sinica, 26, 105-113.

Schaller, G.B., Kang, A., Hashi, T.-D. \& Cai, P. (2007) A winter wildlife survey in the northern Qiangtang of Tibet autonomous region and Qinghai province, China. Acta Theriologica Sinica, 27, 309-316.

VAN ZYL, J.J. (2001) The Shuttle Radar Topography Mission (SRTM): a breakthrough in remote sensing of topography. Acta Astronautica, 48, 559-565.

Vermeulen, C., Lejeune, P., Lisein, J., Sawadogo, P. \& Bouché, P. (2013) Unmanned aerial survey of elephants. PLoS ONE, 8, e5470o.

Watts, A.C., Perry, J.H., Smith, S.E., Burgess, M.A., Wilkinson, B.E., Szantoi, Z. et al. (2010) Small unmanned aircraft systems for low-altitude aerial surveys. Journal of Wildlife Management, 74, $1614-1619$.

World Heritage Encyclopedia (2016) List of endangered and protected species of China. In World Heritage Encyclopedia. Http:// www.worldheritage.org/article/WHEBNoo39183628/List\%20of\% 2oendangered $\%$ 2oand $\%$ 2oprotected $\%$ 2ospecies\%20of $\%$ 20China [accessed o2 February 2018].

Wu, X.M. \& ZHANG, H.F. (2011) Resources regarding populations of Tibetan Antelope (Pantholops hodgsonii) and the status of its protection. Chinese Journal of Nature, 33, 143-148.

XIA, L., YANG, Q., LI, Z. \& FenG, Y.W.Z. (2007) The effect of the Qinghai-Tibet railway on the migration of Tibetan antelope Pantholops hodgsonii in Hoh-xil National Nature Reserve, China. Oryx, 41, 352-357.

Zhang, H., Huang, W., Wei, D. \& Jiang, J. (2016) A wildlife monitoring system based on Tianditu and Beidou: in case of the Tibetan antelope. International Archives of the Photogrammetry Remote Sensing and Spatial Information Sciences, XLI-B4, 259-262.

\section{Biographical sketches}

Hu Jian во is one of the Youth Chief Experts in the Tianjin Research Institute for Water Transportation Engineering. He has focused on remote sensing applications in environmental protection for the past 10 years, mainly in the context of environmental supervision of infrastructure construction projects and ecological surveys for wildlife conservation. WU XI A O M IN works on the protection of threatened species in western China and is a member of the Scientific Committee of the People's Republic of China on Endangered Species. DA I MingXIN is an expert on environmental protection at the Ministry of Transport in China and has focused on environmental impact assessment of transportation engineering for the past 25 years. 